\title{
Research Paper: Word Order Acquisition in Persian Speaking Children
}

\author{
Nahid Jalilevand ${ }^{1 *}$, Mohammad Kamali ${ }^{2}$, Yahya Modarresi ${ }^{3}$, Yalda Kazemi ${ }^{4}$
}

1. Department of Speech and Language Pathology, School of Rehabilitation Sciences, Iran University of Medical Sciences, Tehran, Iran

2. Department of Rehabilitation Management, School of Rehabilitation Sciences, Iran University of Medical Sciences, Tehran, Iran.

3. Department of Linguistics, Institute for Humanities and Cultural Studies, Tehran, Iran

4. Department of Speech Therapy, School of Rehabilitation Sciences, Isfahan University of Medical Sciences, Isfahan, Iran.

chtation: Jalilevand N, Kamali M, Modarresi Y, Kazemi Y. Word Order Acquisition in Persian Speaking Children. Iranian Rehabilitation Journal. 2017; 15(2):111-116. https://doi.org/10.18869/NRIP.IRJ.15.2.111

: https://doi.org/10.18869/NRIP.IRJ.15.2.111

Article info:

Received: 12 Jan. 2017

Accepted: 31 Mar. 2017

\section{Keywords:}

Sentence, Word order, MLU, Normally developing children, Persian

\section{A B STRACT}

Objectives: Persian is a pro-drop language with canonical Subject-Object-Verb (SOV) word order. This study investigates the acquisition of word order in Persian-speaking children.

Methods: In the present study, participants were 60 Persian-speaking children (30 girls and 30 boys) with typically developing language skills, and aged between $30-47$ months. The 30-minute language samples were audio-recorded during free play with an examiner and during description of pictures.

Results: Object-Verb (OV) and subject-verb (SV) sentence structures were the most commonly used in two-component simple sentences. SOV was the most common three-component structures used by Persian-speaking children.

Discussion: Despite the fact that the spoken-Persian language has no strict word order, Persianspeaking children tend to use other logically possible orders of subject (S), verb (V), and object (O) lesser than the SOV structure.

\section{Introduction}

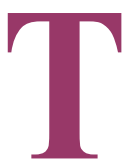

he arrangement of three principal components of a transitive sentence, i.e., Subject $(\mathrm{S})$, Verb $(\mathrm{V})$, and Object $(\mathrm{O})$, forms the word order of a given language. Tomlin surveyed the frequency of word order distribution in different languages and reported the most common word order as SOV and SVO with frequencies of $45 \%$ and $42 \%$, respectively [1]. Other combinations were reported to be less than $10 \%$, including VSO $(9 \%), \operatorname{VOS}(3 \%)$, OSV $(1 \%)$, and OSV ( $0 \%)$. Dryer proposed a two-way typology, based on two binary parameters: whether the language is OV/VO or SV/VS $[2,3]$. The World Atlas of Language Structures defines Persian as an OV/SV language [4].

With regard to word order development, children typically start to combine words between 18 and 24 months of age [5] and quickly follow the word order of their language [6]. Typically developed English-speaking children use the SVO word order in their language development from early

* Corresponding Author:

Nahid Jalilevand, PhD

Address: Department of Speech and Language Pathology, School of Rehabilitation Sciences, Iran University of Medical Sciences, Tehran, Iran. Tel: +98 (21) 22221577

E-mail:jalilevand.n@iums.ac.ir 
years of life [7]. After two-word combinations, and between two and three years of age English-speaking children progress to subject-verb-object sentences [8].

Bates investigated the sentence structures of two Italian children aged 18 and 45 months, respectively [9]. Data were gathered during child-parent communication, and the results showed that the most frequent word order used was SVO, the basic word order in Italian. Slobin and Bever investigated word order in children speaking Turkish, SerboCroat, Italian, and English [10]. They found that children mostly used the canonical word order of their language: the most frequent word order in the speech sample of Turkishspeaking children was SOV (46\%) while Serbo-Croatianspeaking children used SVO $(72 \%)$ more than other combinations [10]. Although all children use a variety of word orders, they tend to use the prominent native language structure more than other structures as is seen in Turkish with SOV word order and Serbo-Croat with SVO combination [1]. In Polish, the basic word order is SVO.

Weist and Witkowska-Stadik [10] surveyed two- and three-word utterances in Polish-speaking children and found that SVO and SOV were the most common arrangements [11]. Sugisaki \& Koji, investigated the early acquisition of basic word order in Japanese and suggested that Japanese children were sensitive to the basic word order even though Japanese is a free word order language [12].

Based on the Theory of Universal Grammar (UG), children are born with an innate knowledge of language. However, there are many variations of grammar rules in different languages, which cannot be covered by a universal grammar rule. The principles and parameters of the theory describe variant rules (parameters) and invariant rules (principles) of various languages [13]. The word order variation and pro-drop $+/$ - are parameters of languages. Persian is a pro-drop language, but English is a non-pro-drop language.

Despite the fact that the canonical word order in Persian is SOV, Persian is categorized as a pro-drop language with null subject, which expresses person and number agreement with the referent on the verb [14]. The Persian verbs have tense markers in order to be coordinated with the subject in person and number. The verb inflections or verb personal endings attach to the verb in order to indicate the person of the verb. So, the transitive or intransitive Persian verb agrees with the subject. Table 1 shows the Persian verb personal endings. It is possible that the SV/OV arrangement also used in a spoken Persian simple sentence.

Native Persian-speaking children developmentally learn the Persian grammatical rules in spoken Persian. Samadi et al. reported that the word order of Persian-speaking children changed from VO to OV because the canonical word order of Persian is SOV [15]. Zolfaghari and Lotfi investigated the sentential word order of 30 Persian-speaking boys aged 3-5 years and reported the word order of different types of sentences included VO, OV, SOV, SV, and SVO [16].

How are words organized and structured in simple sentences by typically developing Persian-speaking children when Persian is a free-word order language? The word order acquisition in early developing stages has not been investigated in the Persian speaking children. The purpose of the current study was to find the most frequent word order of simple sentences spoken by the Persian-speaking children at the ages of 30-47 months. Moreover, the frequency of the other possible word orders in the Persianspeaking children and the relationship between age and research variables was investigated.

\section{Methods}

\section{Participants}

The participants of the study were 60 monolingual Persian-speaking children (30 girls and 30 boys) with normal language development, aged 2.6-3.11 years (30-47 months). All the children attended pre-kindergarten in Tehran city. Based on the Age \& Stage Questionnaire (ASQ) scores [17], their scores for communication, fine motor, gross motor, personal, social, and problem-solving skills were normal. Each domain was scored separately, and then the scores were compared to the screening cut-off score of each domain [17]. The children had no history of neurological problems, seizures, brain damage, or any other disorder and also no symptoms of movement delay.

This study was approved by the Ethics Committee of Iran University of Medical Sciences. The participants were free to withdraw at any stage of the study.

\section{Stimuli}

Language samples were elicited during free play contexts and while talking about 30 pictures. One of the toys was a furnished doll house that included a bedroom set, a dining room set, a bathroom, and a rest room. Four dolls (10 centimeters tall) and two sets of dolls' clothes - one orderly and complete and the other messy and incomplete-provided more stimulant settings for child language elicitation. Other toys included kitchen utensils, balls, animals, cars, toy soldiers, and toy guns. The children were asked to describe 30 colorful pictures $(20 \times 25 \mathrm{~cm})$ representing daily family ac- 
tivities portraying a mother, a father, and children at home, park, doctor's office, birthday party, and seaside.

\section{Procedure of language sample collection}

The examiner gathered the language samples of all children in an appropriate room (with minimum noise and enough light) at each kindergarten. A free play was conducted with each child, and their conversations were recorded to be used as the child's language sample. During the conversation stage, children were encouraged to explain the pictures. Language samples of 20-30 minute conversations between children and the examiner were recorded using a Kingston-DVR-902 digital voice recorder that was placed in a container to avoid distracting the children. The sampling conversation started with 15 minutes of free play followed by a 15 -minute picture description. The language samples of children who were reluctant to communicate, of children aged 30-35 months with less than 50 intelligible utterances, and of children aged 36 months and older with less than 100 intelligible utterances were excluded.

\section{Transcription and coding reliability}

The collected language samples were orthographically transcribed following the Persian Transcription Convention Protocol (PTCP) [18] with coding rules based on the Persian-adapted instruction of Systematic Analysis of Language Transcripts (SALT) software [18, 19]. The repeated utterances, one-word utterances, utterances without a verb were excluded. Word order codes included two-component sentences (i.e., VS, SV, VO, and OV word orders) and three-component sentences (i.e., VOS, OVS, VSO, SVO, OSV, and SOV word orders). Interrogative and imperative sentences with one parameter (verb) and sentences with linking verbs were not coded. A maximum of 50 consecutive utterances from each set- ting of free play and picture description were transcribed to meet the criterion of 100 utterances.

To examine the inter-rater reliability, the first 10 minutes of $20 \%$ of the language samples were re-transcribed by a second transcriber, and the correlation between utterance segmentation and codes were computed. The point-topoint agreement indicated 94\%, 96\%, and 93\% inter-rater agreements for a number of utterances, morphemes, and the codes of word orders, respectively. The frequency of VS, SV, VO, OV, VOS, OVS, VSO, SVO, OSV, and SOV word orders and the MLUs of the language samples [18] were calculated by the SALT.

\section{Statistical analysis}

The data were analyzed using IBM SPSS 17 . Pearson correlation was used to determine the strength of the relationship between continuous variables. The one-way ANOVA was used to compare the three age groups means. A P-value of less than 0.05 was considered significant. The variables were age, age groups, MLU, frequency of simple sentences, frequency of complex sentences, and variety of word order.

\section{Results}

A total of 5688 sentences from language samples of 60 children were analyzed. The test distribution for the MLUm, the MLUw, the percentage simple sentences, and complex sentences were normal. Figure 1 shows the percentage of simple sentences and complex sentences for 3 groups. The correlation coefficients between age and MLUw $(\mathrm{r}=0.62$, $\mathrm{P}=0.0001)$ and MLUm ( $\mathrm{r}=0.61, \mathrm{P}=0.0001)$ were expectedly significant. Correlation coefficient between MLUs and frequency of simple sentences and frequency of complex sentences were significant too. The frequency of simple sentences decreased by MLUw $(\mathrm{r}=-0.88, \mathrm{P}=0.0001)$ and MLUm ( $\mathrm{r}=-0.91, \mathrm{P}=0.0001)$, whereas the frequency of

Table 1. The Persian verb personal endings

\begin{tabular}{|c|c|c|c|}
\hline Verb Personal Endings & Examples & Morphem-by-Morphem Glosses & English \\
\hline - æm (single first person) & mi-xor-æm & IPFV-eat.PRES-1SG.SU & l eat \\
\hline -i (single second person) & mi-xor-i & IPFV-eat.PRES-2SG.SU & You eat \\
\hline -d/-e (single third person) & mi-xor-æd & IPFV-eat.PRES-3SG.SU & She/He eats \\
\hline -im (plural first person) & mi-xor-im & IPFV-eat.PRES-1PL.SU & We eat \\
\hline -id (plural second person) & mi-xor-id & IPFV-eat.PRES-2PL.SU & You eat \\
\hline -ænd (plural third person) & mi-xor-ænd & IPFV-eat.PRES-3PL.SU & They eat \\
\hline
\end{tabular}


Table 2. Mean and standard deviations

\begin{tabular}{|c|c|c|c|c|c|}
\hline Age & $\mathbf{N}$ & MLUm & MLUw & Simple Sentences Percent & Complex Sentences Percent \\
\hline \multicolumn{2}{|c|}{ Groups } & $M(S D)$ & $M(S D)$ & $M(S D)$ & $\mathrm{M}(\mathrm{SD})$ \\
\hline $30-35$ & 20 & $5.92(1.10)$ & $3.71(0.68)$ & $80.88(9.50)$ & 19.12(9.50) \\
\hline $36-41$ & 20 & $7.06(1.30)$ & $4.27(0.59)$ & $72.25(10.01)$ & $27.80(9.98)$ \\
\hline $42-47$ & 20 & $8(1.37)$ & $4.96(0.97)$ & 68.30(10.76) & 31.7(10.76) \\
\hline
\end{tabular}

Iranian Rehabilitation Journal

complex sentences increased by MLUw $(\mathrm{r}=0.88, \mathrm{P}=0.0001)$ and MLUm ( $\mathrm{r}=0.91, \mathrm{P}=0.0001)$.

Table 2 shows the Mean and Standard Deviation of MLUm, MLUw, the frequency of simple sentences, and the frequency of complex sentences for the three age groups. There were significant differences between age groups for $\mathrm{MLUm}, \mathrm{F}(2,57)=15.54, \mathrm{P}=0.001$; MLUw, $\mathrm{F}(2,57)=13.35, \mathrm{P}=0.001$; frequency of simple sentences, $\mathrm{F}(2,57)=8.15, \mathrm{P}=0.001$; and frequency of complex sentences, $\mathrm{F}(2,57)=8.18, \mathrm{P}=0.001$.

Table 3 shows the mean and standard deviation of word order structures percents in simple sentences for 3 groups. As can be seen from the data, SV and OV word orders are the most common two-component structures, and SOV is the most common three-component structures used by Persian-speaking children.As determined by one-way ANOVA, there were no statistically significant differences between group means for (1) $\mathrm{OV}$ word orders $\mathrm{F}(2,57)=0.89, \mathrm{P}=0.41$, (2) $\mathrm{SV}$ word orders $\mathrm{F}(2,57)=0.12, \mathrm{P}=0.88$, (3) SOV word orders $\mathrm{F}(2,57)=1.59, \mathrm{P}=0.21$.

\section{Discussion}

The results showed that the simple sentences decreased whereas the complex sentences increased with the increasing age in children. MLUs were used as a gross index of grammatical development $[20,21]$. The mean of MLUs showed that the children could make utterances of more than four morphemes and more than three words. They mostly tended to produce simple sentences with the verb at the end and in OV and SV structures (two-component structures). The result indicated no significant difference between age groups and frequency of $\mathrm{SV}, \mathrm{OV}$, and SOV word orders, and inferentially, there was no relationship between age and the order of words.

Based on Dryer's suggestion of the typology of language (VS/SV and OV/VO) [1, 2], it appears that Persian-speaking children developmentally tend to use OV or SV word orders in simple sentences. Also, they tended to use null subject sentences by using the OV structure, possibly because person verb markers semantically transfer the meaning of person and number without the need to use subject at the beginning. It might also be related to Persian being

Table 3. Mean and standard deviation word order structures percents $(n=60)$

\begin{tabular}{|c|c|c|c|c|c|c|c|c|c|c|c|}
\hline \multirow{2}{*}{\multicolumn{2}{|c|}{ Age Groups }} & \multicolumn{6}{|c|}{ Three-Component Sentences } & \multicolumn{4}{|c|}{ Two-Component Sentences } \\
\hline & & SOV & SVO & VSO & vos & OVS & OSV & OV & vo & SV & VS \\
\hline \multirow{2}{*}{$\begin{array}{l}30-35 \\
N=20\end{array}$} & Mean & 7.36 & 0.57 & 0.1 & 0 & 0.19 & 0.5 & 24.49 & 0.94 & 16.55 & 1.05 \\
\hline & SD & 4.4 & 0.8 & 0.4 & 0 & 0.4 & 0.9 & 6.7 & 0.9 & 7.6 & 1.3 \\
\hline \multirow{2}{*}{$\begin{array}{l}36-41 \\
N=20\end{array}$} & Mean & 7.46 & 0.59 & 0 & 0 & 0.4 & 0.7 & 27.35 & 2.41 & 16.03 & 0.97 \\
\hline & SD & 5.2 & 1.7 & 0 & 0 & 0.6 & 0.3 & 6.2 & 2.2 & 5.2 & 1.01 \\
\hline \multirow{2}{*}{$\begin{array}{l}42-47 \\
N=20\end{array}$} & Mean & 9.73 & 0.44 & 0 & 0 & 0.2 & 0.13 & 26.55 & 2.46 & 17.04 & 0.34 \\
\hline & SD & 4.5 & 0.7 & 0 & 0 & 0.6 & 0.6 & 7.8 & 1.9 & 6.32 & 0.74 \\
\hline
\end{tabular}

Iranian Rehabilitation Journa

SOV: Subject+Object+Verb; SVO: Subject+Verb+Object; VSO: Verb+Subject+Object;VOS:Verb+Subject+Object; OSV: Object+Subject+Verb; OVS: Object+Verb +Subject; OV: Object+Verb; VO: Verb+Object; SV: Subject+Verb; VS: Verb+Subject 


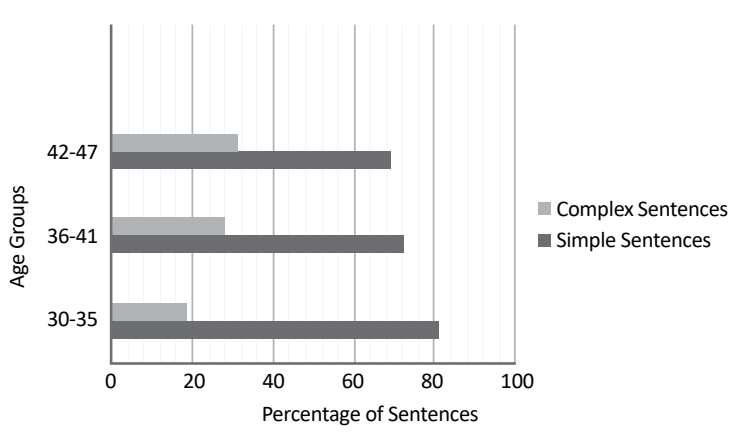

Iranian Rehabilitation Journal

Figure 1. Percentage of simple and complex sentences for three groups $(n=60)$

a pro-drop language. As it can be seen in example 1, produced by a 40-month-old child, the verb marker indicates the plural third person. It is possible that the pronoun as a subject was omitted in the example.

Example 1: OV word order

In=o negā mi-kon-æn

\section{This=OM look IPFV-do.PRES-3PL.SU}

They are looking at this.

This phenomenon occurs in both pro-drop and non-prodrop languages. Hyams argued that all children begin from a pro-drop structure and progress to the non-pro-drop although English is a non-pro-drop language [22]. The subject omission in the language development is related to the subject omission in the pro-drop languages such as Italian and Spanish [23]. The SOV structure could be changed to OV arrangement by pro-dropping. Therefore, the Persianspeaking children begin from a pro-drop structure but they do not progress to the non-pro-drop structure.

The SV structures were found to be used more frequently. Some sentences that need an object were produced with SV structure by the children (infrequently) because the object of sentences was omitted. In Persian, six dependent personal pronouns: -cem (me), -et (you), -eš (him, her, it), -eman (us), -etan (you), -ešan (them) could be used as object agreement markers, so some information about objects can be conveyed by them. Example 2 shows SV word order produced by a 44-month-old child where the object was used by the dependent personal pronoun.

Example 2: SV word order

In dust-eš dār-e

He/She friend-3SG.POS have.PRES-3SG.SU
He/She love her/him.

Examples 1 and 2 show that Persian-speaking children omit the subject in OV structure and the object in SV structure assuming that the listener would perceive the subject and object embedded in the respective verbs. As a result, Persian speaking children could use correct sentences with two parameters - OV/SV - as proposed by Dryer [2, 3]. Zolfaghari and Lotfi also reported that the two-component structures with VO, OV, SV sentential word orders were used by Persian-speaking children aged 3-5 years [16].

The result showed that Persian-speaking children could formulate multi-word sentences because the average of their MLUs in words is greater than three, but for using simple sentences, they used two-component sentences more frequently than three-component structures. Therefore, subject omission in Persian-speaking children cannot be attributed to their limited ability for making long sentences. So when the Persian-speaking children tend to use OV/SV structure, they tend to use the canonical structure of their language. This result did not confirm the suggestion of Bloom [24] that subject omission in the early stages of language development is the result of limited ability to lengthen sentences.

Similar to English-speaking children that use verbs before the object in the multi-word stage of language development [25], the Persian-speaking children also tend to follow the canonical word order of their mother tongue. Although Persian is a free word order language, for three-component structures the children used the SOV structure more than other possible basic word orders. Wells reported that English-speaking children master the common English word order (SVO) at 30 months of age [26]. Persian-speaking children could also use the canonical Persian language word order (SOV) at 30-35 months of age.

The SOV structure, more than other structures, provide evidence for this claim that children are sensitive to the standard structure of their own languages, which is consistent with the previous report by Sugiasaki and Koji [12] Bates demonstrated that Italian-speaking children produced SOV more frequently than any other structures [9]. There are six possible word orders in the Italian language, and the children use the OSV/SOV structure less than $1 \%$ of the time. Slobin and Bever showed that the Turkish children use SOV and that Serbo-Croatian children use SVO more than other structures [10]. Weist and Witkowska-Stadik and Slobin and Bever $[10,11]$ reported that children can use other structures too. According to the Samadi et al. Persian-speaking children tend to use the canonical structure of their mother tongue [15] and according to the results of our study, although the Persian-speaking children may use 
other structures for simple sentences with a three-component structure, but SOV was the most prominent structure observed at these particular age levels.

\section{Conclusion}

Persian-speaking children tend to use a verb at the end of their sentences. Moreover, OV and SV were the most common word orders for two-component sentences. The Persian-speaking children mostly tend to use the SOV structure for three-component sentences, and scarcely use other logically possible orders of $\mathrm{S}, \mathrm{V}$, and $\mathrm{O}$. As a result, the Persian-speaking children's most common word orders of simple sentences are OV, SV, and SOV.

\section{Acknowledgments}

This investigation was supported by the education grant 320-3246-93-9-9 from the Vice-Chancellor for Research at Iran University of Medical Sciences. The authors would like to thank Amir Hossain Mashreghi, Navid Samavatian, Sahar Mafian, Tahmine Maleki, Fateme Babajani, Samane Babajani, and Marziye Faraji for their valuable contributions.

\section{Conflict of Interest}

The authors declared no conflicts of interest.

\section{References}

[1] Tomlin RS. Basic word order: Functional principles. London Croom Helm; 1986.

[2] Dryer MS. SVO languages and the OV: VO typology. Journal of Linguistics. 1991; 27(02):443-82. doi: 10.1017/s0022226700012743

[3] Dryer MS. On the six-way word order typology. Studies in Language. 1997; 21(1):69-103. doi: 10.1075/sl.21.1.04dry

[4] Haspelmath M. World atlas of language structures. Oxford: Oxford University Press; 2005.

[5] Hoff E. Language development. Boston: Cengage Learning; 2009.

[6] Foster-Cohen SH. An introduction to child language development. London: Routledge; 2013.

[7] Benson JB, Haith MM. Language, memory and cognition in infancy and early childhood. NewYork: Elsevier; 2009.

[8] Pastorino E, Doyle-Portillo S. What is psychology? Essentials. Wadsworth: Wadsworth Publishing Company; 2013.

[9] Bates E. Language and context: The acquisition of pragmatics. New York: Academic Press; 1976
[10] Slobin DI. Cross linguistic study of language acquisition. New York: Lawrence Erlbaum Associates Publishers; 1986.

[11] Weist RM, Witkowska-stadnik K. Basic relations in child language and the word order myth. International Journal of Psychology. 1986; 21(1-4):363-81. doi: 10.1080/00207598608247595

[12] Sugisaki K. Early acquisition of basic word order in Japanese. Language Acquisition. 2008; 15(3):183-91. doi: $10.1080 / 10489220802142441$

[13] Chomsky N. Principles and parameters in syntactic theory. In: Hornstein N, Lightfoot D, editors. Explanation in linguistics: The logical problem of language acquisition. London: Longman; 1981.

[14] Mahootian S. Persian (Descriptive grammars). London: Routledge; 1997.

[15] Samadi H, Perkins MR. P-LARSP: A developmental language profile for Persian. Clinical Linguistics \& Phonetics. 1998; 12(2):83-103. doi: 10.3109/02699209808985215

[16] Zolfaghari M, Lotfi AR. Iranian children's systematic sentential word order within P \& P model. International Journal for Teachers of English. 2014; 4(3):17-36.

[17] Sajedi F, Vameghi R, Kraskian Mojembari A, Habibollahi A, Lornejad H, Delavar B. [Standardization and validation of the ASQ developmental disorders screening tool in children of Tehran city (Persian)]. Tehran University Medical Journal. 2012; 70(7):436-446

[18] Kazemi Y, Klee T, Stringer H. Diagnostic accuracy of language sample measures with Persian-speaking preschool children. Clinical Linguistics \& Phonetics. 2015; 29(4):304-18. doi: 10.3109/02699206.2014.1003097

[19] Miller JF, Iglesias A. Systematic analysis of language transcripts (SALT, version 8). Middleton: SALT Software LLC; 2012.

[20] Brown R. A first language: The early stages. Cambridge: Harvard University Press; 1973

[21] Klee T, Fitzgerald MD. The relation between grammatical development and mean length of utterance in morphemes. Journal of Child Language. 1985; 12(02): 251-69. doi: 10.1017/ s0305000900006437

[22] Hyams N, Wexler K. On the grammatical basis of null subjects in child language. Linguistic Inquiry. 1993; 24(3): 421-459.

[23] Hyams NM. Language acquisition and the theory of parameters. Dordrecht: Reidel; 1986

[24] Bloom P. Subject less sentences in child language. Linguistic Inquiry. 1990; 21(4):491-504.

[25] Bloom L. Language development: Form and function in emerging grammars. Cambridge: MIT Press; 1970.

[26] Wells G. Language development in the pre-school years. Cambridge: Cambridge University Press; 1985. 